\title{
Т.П. Серебренникова
}

\section{О ВЛИЯНИИ ИЗМЕНЕНИЙ НОРМАТИВНОЙ БАЗЫ ПО АТТЕСТАЦИИ КАДРОВ ВЫСШЕЙ КВАЛИФИКАЦИИ В РОССИЙСКОЙ ФЕДЕРАЦИИ НА КОЛИЧЕСТВО ЗАЩИТ ДИССЕРТАЦИЙ В ТОМСКОМ ГОСУДАРСТВЕННОМ УНИВЕРСИТЕТЕ (2000-2016 ГГ.)}

\begin{abstract}
Анализируются основные изменения в законодательстве Российской Федерации по аттестации научных и научно-педагогических кадров высшей квалификации. Проведено исследование потока диссертаций, подготовленных либо защищенных на базе Томского государственного университета. Выявлены количественное распределение диссертаций по отраслям наук и динамика защит за период с 2000 по 2016 г. Отдельно рассмотрены количественное распределение по научным специальностям и динамика защит диссертаций по историческим наукам. Показано влияние изменений в нормативной базе на количество защит.

Ключевые слова: аттестация кадров высшей квалификации; наукометрический анализ; Томский государственный университет.
\end{abstract}

Качество образования определяет состояние и перспективы развития общества. Особое место в структуре высшего образования занимают аспирантура и докторантура, являющиеся институтами по подготовке научных и научно-педагогических кадров высшей квалификации. Так как состояние послевузовского образования в настоящее время становится одним из значимых показателей в рейтинговой оценке университета, актуальными являются обобщение и анализ работы этих институтов в современной России.

Научная литература, посвященная различным аспектам подготовки научных и научно-педагогических кадров в СССР, в современной России и Сибири, обширна (работы А.С. Бутягина, Ю.А. Салтановой, Е.В. Чуткерашвили, К.Т. Галкина, В.В. Петрика, С.А. Красильникова, С.В. Кононовой, М.Н. Маресовой, Т.С. Бендюковой и др.). Целый ряд исследований (монографий, диссертаций, статей) по данной проблематике принадлежит историкам Томского государственного университета (С.Ф. Фоминых, С.А. Некрылов, А.В. Литвинов, К.В. Петров, К.В. Зленко, А.С. Ульянов, С.А. Меркулов, Н.П. Цеховой, Д.В. Хаминов, М.В. Грибовский, А.Н. Сорокин и др.). Наиболее острые и злободневные вопросы подготовки научно-педагогических кадров обсуждаются на страницах научных журналов «Вопросы образования», «Высшее образование в России», «Alma Mater», «Социология образования» и др.

Принимая во внимание, что одним из показателей развития науки является рост ее количественных информационных параметров, большую роль для раскрытия темы играют работы, посвященные библиометрии и наукометрии. Теоретико-методологические основы количественного изучения документального потока в России были заложены В.В. Налимовым, А.И. Михайловым, Ю.В. Грановским. Реформы российской науки, в рамках которых наукометрические показатели были объявлены мерой результативности научных коллективов и отдельных сотрудников, стали причиной всплеска публикаций по библиометрии и наукометрии (по подсчетам А.Е. Гуськова, только за 2000-2014 гг. не менее 766 публикаций [1]).
Постоянная модернизация высшего образования в России требует научного обоснования и анализа последствий предполагаемых изменений, что вызывает необходимость продолжения исследований по данной проблематике. В этом отношении целесообразным представляется рассмотрение указанной проблемы на примере Томского государственного университета (ТГУ). В настоящее время здесь работает более 600 докторов наук и свыше 1300 кандидатов наук, функционируют 22 докторских диссертационных совета. В ТГУ сформировался широкий спектр научных школ, сохраняющих и развивающих богатые исследовательские традиции. Так как одним из масштабных результатов изучения каких-либо вопросов являются диссертационные исследования, то целью статьи является установление степени влияния на динамику защит диссертаций в ТГУ изменений в нормативном обеспечении аттестации научных и научно-педагогических кадров высшей квалификации.

В качестве источников выступили документы текущего архива отдела диссертационных советов ТГУ, сборники «Итоги научно-исследовательской деятельности» за 2001-2016 гг. Для выявления изменений в нормативной базе использовались выпуски «Бюллетеня Высшей аттестационной комиссии Министерства образования и науки Российской Федерации» за 20002016 гг., в котором публикуются основные документы, регламентирующие аттестацию научных и научно-педагогических работников.

Одним из основных методов исследования стал наукометрический анализ, сущность которого заключается в подсчете, сочетании, истолковании и сравнении элементов научного документопотока. Для выявления количественных параметров документопотока использовались следующие критерии: хронология защит диссертаций; ученые степени, на соискание которых защищены диссертации; распределение диссертаций по научным отраслям.

За рассматриваемый период произошли значительные изменения в аттестации научных и научно-педагогических кадров - реструктуризация сети диссертационных 
советов, создание новой номенклатуры специальностей, разработка паспортов научных специальностей с характеристикой их направлений, установление перечня дисциплин, по которым должны сдавать экзамены соискатели ученой степени кандидата наук, повышение требований к диссертационным работам (введение Перечня научных журналов для опубликования основных результатов диссертационных исследований с установлением минимального количества статей, введение в действие системы «Антиплагиат») и др.

Для определения влияния изменений в нормативной базе на динамику защит были рассмотрены метаданные 2722 диссертаций на соискание ученой степени кандидата наук и 553 диссертаций на соискание ученой степени доктора наук. На протяжении исследуемого периода диссертации защищались по 19 отраслям наук. Наибольшее их количество защищено по физико-мате- матическим наукам (22,6 \% от общего числа диссертаций). Одной из причин опережающего роста явилось преобладающее количество диссертационных советов в ТГУ по этой отрасли (в рассматриваемый период от 7 до 10). Удельный вес защит по историческим наукам составил $12,3 \%$, по филологическим - 11,6 \%, биологическим - 9,6\%, юридическим - 8,8 \%, философским $7,8 \%$, экономическим - 7,2 \%, техническим $-4,5 \%$, психологическим $-4,1 \%$, химическим $-3,4 \%$, географическим - 3,1 \%, геолого-минералогическим - 1,9\%, педагогическим $-1,7 \%$, социологическим - 0,2 \%, медицинским - 0,2 \%, политическим - 0,1\%. Кроме того, две диссертации на соискание ученой степени доктора культурологических наук и по одной кандидатской диссертации по искусствоведческим и сельскохозяйственным наукам были защищены соискателями ТГУ в сторонних советах.

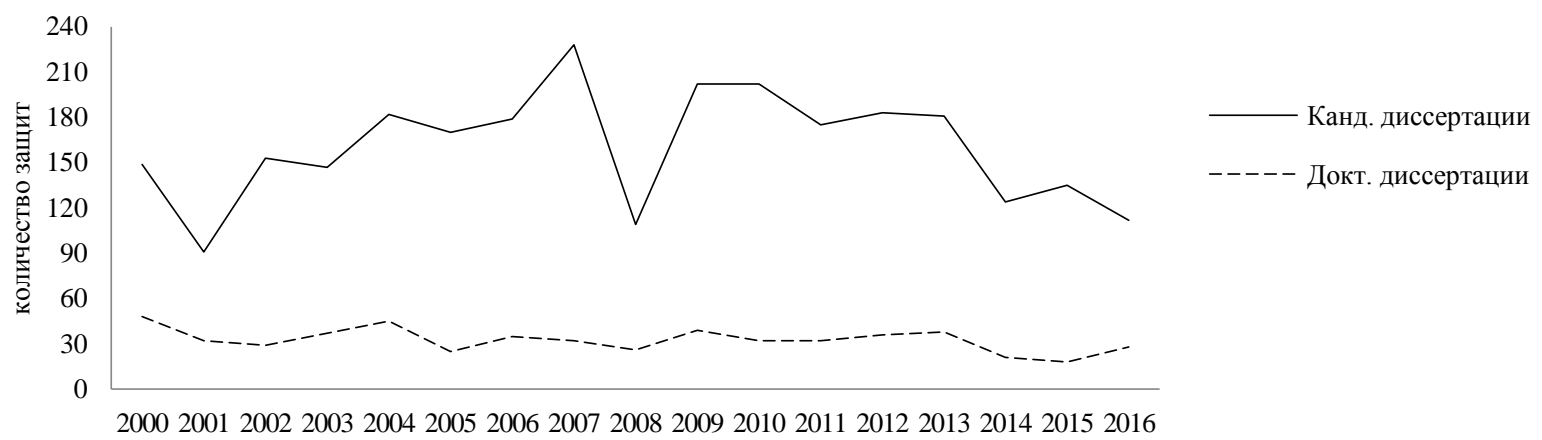

Рис. 1. Динамика защит диссертаций в 2000-2016 гг. в Томском государственном университете

Как видно из рис. 1, общая динамика защит диссертационных исследований носит волнообразный характер. Наибольшая глубина падений пришлась на 2001, 2008 и 2014 гг. Так, в 2001 г. количество защищенных диссертаций уменьшилось на 37,6 \% по сравнению с 2000 г. Одной из основных причин снижения явилось переутверждение в РФ сети диссертационных советов и снижение их числа, в том числе в ТГУ с 23 в 2000 г. до 21 в 2001 г.

Принятое Правительством Российской Федерации 30 января 2002 г. постановление № 74 «Об утверждении положения о порядке присуждения ученых степеней», повысившее требования к докторским диссертациям, привело к уменьшению их защит в целом по стране на 22,5 \%. Однако произошедшие изменения не отразились на количестве защит докторских диссертаций в ТГУ. Напротив, их рост в 2003 г. составил 21,6\% по сравнению с 2002 г. Число защищенных кандидатских диссертаций после уменьшения в 2001 г. (на 38,9 \% относительно 2000 г.), также увеличивалось.

Для улучшения ситуации в системе подготовки кадров высшей научной квалификации Правительством Российской Федерации 20 апреля 2006 г. были утверждены изменения в «Положении о порядке присуждения ученых степеней», которые ввели ряд прямых норм, направленных на повышение требовательности к соискателям ученых степеней. В частности, произошло расширение гласности в системе аттестации кадров высшей квалификации - представление в обязательном порядке авторефератов и объявлений о защитах диссертаций на сайтах Высшей аттестационной комиссии (ВАК) и диссертационных советов. В целях обеспечения публичной ответственности диссертантов была введена обязательная публикация результатов исследований в ведущих научных журналах, включенных в Перечень ВАК (данная редакция Положения не устанавливала минимальное количество публикаций для докторской диссертации, результаты кандидатской диссертации должны были быть опубликованы хотя бы в одной статье) [2. С. 2-4]. Такие изменения в целом не отразились на количестве защит диссертаций в 2007 г. Несмотря на небольшой спад докторских защит (на 8,5\%), наблюдался значительный рост кандидатских диссертаций (на 21,5 \%), что обеспечило наибольшее годовое число защит за весь рассматриваемый период.

В целях борьбы с недобросовестным заимствованием в 2007 г. была введена система «Антиплагиат», которая явилась одной из причин снижения числа защит диссертаций в 2008 г. [3. С. 7]. В ТГУ спад количества защит по докторским диссертациям составил $18,8 \%$, по кандидатским - 52,2\%.

Дальнейшее повышение требований к соискателям ученых степеней произошло в 2013 г. Согласно постановлению Правительства РФ от 24 сентября 2013 г. № 842 
«О порядке присуждения ученых степеней» было установлено ограничение для соискателей ученой степени кандидата наук, имеющих высшее образование, подтвержденное дипломом бакалавра. Защита работ должна была пройти не позднее 1 июля 2014 г. Впоследствии представить к защите диссертацию на соискание ученой степени кандидата наук могли только лица, имеющие высшее образование, подтвержденное дипломом специалиста или магистра.

Изменения затронули также порядок опубликования основных научных результатов диссертаций на соискание ученой степени. В частности, монографии перестали относиться к обязательным публикациям. Были установлены минимальные нормы по количеству статей, опубликованных в журналах, включенных в Перечень ВАК. Количество публикаций, в которых излагаются основные научные результаты диссертации на соискание ученой степени доктора наук, в рецензируемых изданиях: в области искусствоведения и культурологии, социально-экономических, общественных и гуманитарных наук - не менее 15 , в остальных областях - не менее 10. Количество публикаций, в которых изложены основные научные результаты диссертации на соискание ученой степени кандидата наук, в рецензируемых изданиях: в области искусствоведения и культурологии, социально-экономических, общественных и гуманитарных наук - не менее 3 , в остальных областях - не менее 2 [4]. В результате количество защит докторских диссертаций в 2014 г. сократилось на 44,7 \%, кандидатских - на 31,5 \%, оставаясь в 2015-2016 гг. примерно на том же уровне.

Подобная динамика защит характерна и для отдельных отраслей наук. В качестве примера рассматривались диссертации, защищенные по историческим наукам. Исторические исследования в ТГУ имеют глубокие корни и традиции. Историко-филологический факультет, созданный 1 июля 1917 г. указом Временного правительства России, стал базовым для открытия новых гуманитарных факультетов в ТГУ и ряде других университетов Сибири, которым он передал свои традиции и кадры [5. С. 85]. За время своей деятельности факультет дал науке немало видных деятелей - основателей научных школ и направлений в ряде областей знаний. На современном этапе ТГУ продолжает сохранять статус одного из ведущих научно-образовательных центров Сибири и Дальнего Востока по подготовке историков и проведению научных исследований [6. С. 249].

В настоящее время на историческом факультете функционирует два докторских диссертационных совета - Д 212.267.03 (председатель - д-р ист. наук, профессор В.П. Зиновьев, заместитель председателя - д-р ист. наук, профессор О.А. Харусь, ученый секретарь д-р ист. наук, доцент В.В. Шевцов) и Д 212.267.18 (председатель - д-р ист. наук, профессор С.Ф. Фоминых, заместители председателя - д-р ист. наук, професcop С.А. Некрылов, д-р ист. наук О.М. Рындина, ученый секретарь - канд. ист. наук М.В. Грибовский), в которых защита проводится по 6 научным специальностям.

В 2000-2016 гг. диссертации на историческом факультете защищались по 7 специальностям: 07.00.02 Отечественная история, 07.00.03 - Всеобщая история (новое и новейшее время), 07.00.06 - Археология, 07.00.07 - Этнография, этнология и антропология, 07.00.09 - Историография, источниковедение и методы исторического исследования, 07.00.10 - История науки и техники, 24.00.03 - Музееведение, консервация и реставрация историко-культурных объектов (исторические науки). Всего за этот период было защищено 403 диссертации по историческим наукам, в том числе 63 докторских. В период с 2001 по 2013 гг. наблюдалась устойчивая тенденция роста количества защит, особенно в 2007-2013 гг. (2007 г. - 32, 2008 г. - 28, 2009 г. 37, 2010 г. - 38, 2011 г. - 34, 2012 г. - 28, 2013 г. - 31). Затем произошел существенный спад (2014 г. - 10 и 2016 г. - 12 защит) (рис. 2).

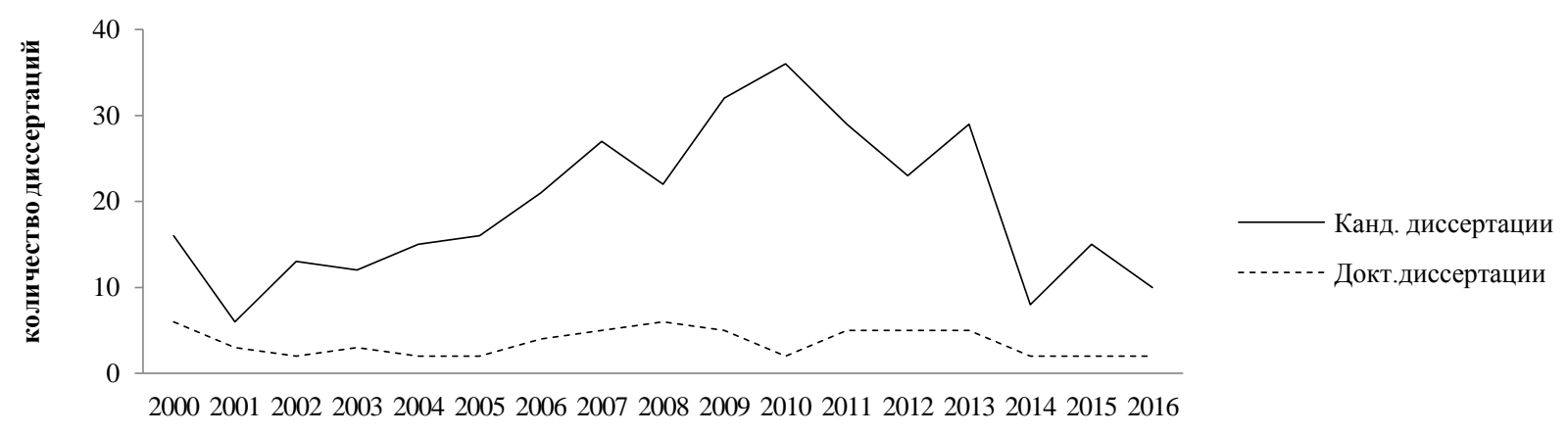

Рис. 2. Динамика защит диссертаций по историческим наукам в ТГУ в 2000-2016 гг.

Наибольшее количество диссертаций было защищено по специальности 07.00 .02 - 155 работ (38\% от общего числа диссертаций), в том числе 39 докторских диссертаций, что может свидетельствовать о сформированности научной школы по данному направлению.
По специальности 07.00.03 защищено 84 диссертации (21\%), из них только 6 докторских. Рост числа защит начинается с 2009 г. По специальности 07.00.09 - 69 работ (17\%), в том числе 13 докторских. В 2000-2013 гг. защищалось от 2 до 8 работ в год. В 2014 г. и 2016 г. 
защит по данной специальности не проводилось. 47 диссертаций защищено по специальности 07.00.07 (12\%), причем все - на соискание ученой степени кандидата наук. Наибольшее их количество - в 2010 г. (8), в последующие годы наблюдается тенденция к снижению (1-3 защиты в год). По специальности 07.00.10 - 28 работ (7\%), в том числе 2 докторские. Наибольшее количество (по 5 кандидатских диссертаций) - в 2010 и 2011 гг. По специальности 24.00.03 - 15 диссертаций (4\%), из них 2 докторские. Защиты проходили в 2011-2016 гг. (кроме 2014 г.). Наименьшее количество диссертаций было защищено по специальности 07.00.06 - 5 работ (1\%), из них 1 докторская. Защиты состоялись в 2006, 2007 и 2012 гг.

Таким образом, серьезные изменения в системе аттестации научных и научно-педагогических кадров в начале XXI в. в Российской Федерации, направленные на повышение требований к соискателям ученых степеней, существенно повлияли на динамику защит диссертационных исследований в Томском государственном университете, обусловив их значительное сокращение в последние годы.

\section{ЛИТЕРАТУРА}

1. Гуськов В.А. Российская наукометрия: обзор исследований // Библиосфера. 2015. № 3. С. 75-86.

2. Решение Высшей аттестационной комиссии министерства образования и науки Российской Федерации по вопросу совершенствования государственной аттестации научных и научно-педагогических работников высшей квалификации от 17 декабря 2007 г. // Бюллетень Высшей аттестационной комиссии. 2008. № 2. С. 2-4.

3. Аристер Н.И., Резник С.Д. Управление диссертационным советом : практ. пособие. М. : ИНФРА-М, 2009.464 с.

4. О порядке присуждения ученых степеней» (вместе с «Положением о присуждении ученых степеней») : постановление Правительства РФ от 24.09.2013 № 842. URL: http://www.consultant.ru/document/cons_doc_LAW_152458/ (дата обращения: 21.03.2017).

5. Хаминов Д.В. Становление и развитие исторических научных школ и направлений в Томском государственном университете в 19401980-е гг. // Вестник Томского государственного университета. 2009. № 326. С. 85-90.

6. Хаминов Д.В. Историческое образование и наука в Томском университете в конце ХІХ - начале ХХІ в. Томск : Изд-во Том. ун-та, 2011.270 с.

Serebrennikova Tamara P. Tomsk State University (Tomsk, Russia). E-mail: serebrennikva-tma@ rambler.ru

ON THE INFLUENCE OF THE REGULATORY FRAMEWORK FOR HIGHEST QUALIFICATION PERFORMANCE REVIEW IN THE RUSSIAN FEDERATION ON THE QUANTITY OF THESES DEFENSES AT TOMSK STATE UNIVERSITY (2000-2016)

Keywords: dissertation; scientometric analysis; Tomsk State University.

The article elaborates on the influence of the regulatory framework for highest qualification performance review in the Russian Federation on the quantity of theses defenses at Tomsk State University in 2000-2016.

The sources for the research are documents from the Tomsk State University current archive, the "Itogi nauchno-issledovatel'skoi dejatel'nosti" ("Results of Research Activities") digests, editions of the "Byulleten' Vysshej attestacionnoj komissii Ministerstva obrazovaniya i nauki Rossijskoj Federacii" ("Bulletin of Higher Attestation Commission of the Ministry of Education and Science of the Russian Federation") for 2000-2016. Scientometric analysis was one of the main research methods. In order to determine the quantitative parameters of the document flow, we applied the following criteria: theses defenses timeline; degrees sought by the researchers; theses allocation into branches of science.

Overall, we studied 2722 Candidate of Sciences theses and 533 Doctor of Sciences theses.

The performed research allowed us to state significant changes to the system of highest qualification performance review during the studied period: restructuring the theses committees network, establishing the new program nomenclature, introducing the passports of scientific programs, tightenening the requirements for theses (introducing the List of scientific journals to publish the main results of researches with the minimal number of articles published, implementing the new "Antiplagiat" (anti-plagiarism) system.

Changes in the regulatory framework affected the number of theses defenses. The lowest number of theses were defended in 2001, 2008, and 2014. The highest number was reached in 2007. Throughout the studied period, researchers defended theses in 19 branches of science at TSU.

We separately studied the qualitative allocation into scientific programs and the dynamics of theses defenses in historical sciences.

Overall, 403 theses in historical sciences were defended. For the period between 2001 and 2013, we observed a stable trend of increasing number of theses defenses, especially in 2007-2013, which was followed by a substantial drop. The highest number of theses were defended in the "Domestic History" program (38\% of the total number of theses).

Thus, significant alterations were made in the system of performance review for academic personnel at the beginning of XXI century in the Russian Federation. Those changes tightened the requirements for degree candidates and substantially affected the dynamics of theses defenses at Tomsk State University.

\section{REFERENCES}

1. Guskov, V.A. (2015) Rossiyskaya naukometriya: obzor issledovaniy [Russian scientometrics: a review of researches]. Bibliosfera - Bibliosphere. 3. pp. 75-86.

2. Higher Attestation Commission of the Ministry of Education and Science of the Russian Federation. (2008) Reshenie Vysshey attestatsionnoy komissii ministerstva obrazovaniya i nauki Rossiyskoy Federatsii po voprosu sovershenstvovaniya gosudarstvennoy attestatsii nauchnykh i nauchno-pedagogicheskikh rabotnikov vysshey kvalifikatsii ot 17 dekabrya $2007 \mathrm{~g}$. [The decision of the Higher Attestation Commission of the Ministry of Education and Science of the Russian Federation on improving state certification of scientific and scientific-pedagogical personnel of higher qualification from December 17, 2007]. Byulleten' Vysshey attestatsionnoy komissii. 2. pp. 2-4.

3. Arister, N.I. \& Reznik, S.D. (2009) Upravlenie dissertatsionnym sovetom [Managing the Dissertation Board]. Moscow: INFRA-M. 
4. The Government of the Russian Federation. (2013) Postanovlenie Pravitel'stva RF ot 24.09.2013 № 842 "O poryadke prisuzhdeniya uchenykh stepeney" (vmeste s "Polozheniem o prisuzhdenii uchenykh stepeney") [Resolution of the Government of the Russian Federation of September 24, 2013 № 842 "On the procedure for awarding academic degrees" (together with the "Regulations on awarding academic degrees")]. [Online] Available from: http://www.consultant.ru/document/cons_doc_LAW_152458/. (Accessed: 21st March 2017).

5. Khaminov, D.V. (2009) Stanovlenie i razvitie istoricheskikh nauchnykh shkol i napravleniy v Tomskom gosudarstvennom universitete v 1940-1980-e gg. [Formation and development of history scientific schools in Tomsk university in 1940-1980]. Vestnik Tomskogo gosudarstvennogo universiteta Tomsk State University Journal. 326. pp. 85-90.

6. Khaminov, D.V. (2011) Istoricheskoe obrazovanie i nauka v Tomskom universitete v kontse XIX - nachale XXI v. [Historical education and science in Tomsk university in the late 19th - early 21 st centuries]. Tomsk: Tomsk State University. 